\title{
Trends in research related to "Shinrin-yoku" (taking in the forest atmosphere or forest bathing) in Japan
}

\author{
Yuko Tsunetsugu $\cdot$ Bum-Jin Park · Yoshifumi Miyazaki
}

Received: 18 July 2008/Accepted: 27 May 2009/Published online: 9 July 2009

(C) The Japanese Society for Hygiene 2009

\begin{abstract}
Shinrin-yoku", which can be defined as "taking in the forest atmosphere or forest bathing", has been receiving increasing attention in Japan in recent years for its capacity to provide relaxation and reduce stress. Since 2004, the authors of this paper have been involved in an investigation designed to ascertain the physiological effects of "Shinrin-yoku" within the framework of the "Therapeutic Effects of Forests" project. We have conducted physiological experiments, both in actual forests and in the laboratory, to elucidate the physiological effects on individuals of exposure to the total environment of forests or to only certain elements of this environment, such as the odor of wood, the sound of running stream water, and the scenery of the forest. We have obtained physiological measurements of central nervous activity, autonomic nervous activity, and biomarkers reflecting stress response that can be applied in this line of approach. Using these measurements, we have summarized the separate elements of forests in terms of the five senses. We have also reviewed a selection of field studies and introduced a number of results from ongoing projects as well as those from early studies. Future perspectives are also discussed.
\end{abstract}

Keywords Field study - Forest bathing .

Heart rate variability (HRV) .

Near-infrared spectroscopy (NIRS) · Salivary cortisol

Y. Tsunetsugu ( $\square)$

Forestry and Forest Products Research Institute,

1 Matsunosato, Tsukuba, Ibaraki 305-8687, Japan

e-mail: yukot@ffpri.affrc.go.jp

B.-J. Park · Y. Miyazaki

Center for Environment, Health and Field Sciences,

Chiba University, Kashiwa, Japan

\section{Introduction}

In a survey conducted by the Ministry of Health, Labour and Welfare of Japan [1], $54.2 \%$ of the respondents $(32,000$ Japanese individuals older than 12 years) rated their stress level as "very high" or "relatively high." This figure, however, represents only an average of the assessments made by all the respondents, and in certain age groups the proportion of individuals who reported experiencing excessive stress was as high as $60-70 \%$. Furthermore, in self-perceived health status evaluations, almost half $(42.3 \%)$ of the surveyed individuals rated their health status as "mediocre" on a five-grade "poor"-to-"good" scale. These data clearly indicate that modern societies are "highstress" societies and that many individuals, although not actually affected by any particular disease, perceive themselves as unhealthy.

In Japan, "Shinrin-yoku", which can be defined as "taking in the forest atmosphere or forest bathing" is currently receiving increasing attention for its capacity to provide relaxation and reduce stress. Humans empirically recognize that getting in touch with nature provides a feeling of comfort. In carrying out their investigations on "Shinrin-yoku", the authors of this article have assumed that the reason underlying this feeling of comfort with "nature" or "natural matters" is closely linked with the human evolutionary process. Frumkin supports this view and reports that a deep-seated connection between the natural world and humans is unsurprising from an evolutionary perspective [2]; based on this description, we have also assumed that human physiological functions have had to adapt to the natural environment through the course of evolution. Consequently, living in our modern "artificial" society is inherently stressful. Given this background, it should be natural for 
humans to feel a sense of comfort or affinity with the natural environment.

"Shinrin-yoku" is considered to be one of the most accessible ways to get in touch with the natural world and to lower excessive stress to levels that are commensurate with what our bodies are "expected" to cope with. In Western societies, this approach has been incorporated into the lives of individuals since the nineteenth century. The best known example of this may be Kneipp therapy in Germany. Kneipp therapy utilizes forests mainly as the fields for exercise therapy, which is one of the five pillars of the method. However, although Kneipp therapy somewhat realizes the concept of "Shinrin-yoku" in a practical context, its precedents in the Western countries are based mostly on empirical knowledge. The effects of "Shinrinyoku" have yet to be verified by scientific evidence.

The term "Shinrin-yoku" and its concept were introduced in Japan by the Forest Agency of the Japanese government in 1982. Over the 25 years that have passed since then, interest in stress control or relaxation among those living in our modern-day society has greatly increased. In addition, in the fields of medicine and nursing, there has been a trend toward evidence-based medicine or nursing, emphasizing the need for scientific evidence. Based on this social background, in 2005, the Forest Agency instituted the "Therapeutic Effects of Forests Plan," which emphasizes the importance of scientific investigation.

Since 2004, the authors have been involved in investigations designed to ascertain the physiological effects of "Shinrin-yoku" within the context of the "Therapeutic Effects of Forests" project. We have conducted physiological experiments both in actual forests and in the laboratory in order to elucidate the physiological effects of the total forest environment or certain elements of the forest environment, such as the odor of wood, the sound of running stream water, and the scenery of the forest. In this paper, we introduce the physiological measurements of central nervous activity, autonomic nervous activity, and biomarkers reflecting stress response that can be applied in this approach. Related studies that have been conducted in Japan will also be reviewed; further, in the final section, we will briefly discuss future perspectives.

\section{Physiological evaluation of "Shinrin-yoku"}

In order to investigate the physiological effects of "Shinrinyoku", it is essential to conduct field experiments. However, since it is more difficult to control the experimental conditions in the field than in the laboratory, there are certain practical requirements associated with measuring physiological parameters under field conditions such as: (1) the measurement device should be portable and able to withstand vibrations on being moved; (2) a simple measurement process and short measurement time is preferable; (3) measurement error due to environmental factors, such as temperature, wind, light, and noise, should be avoided; (4) battery-powered equipment is preferable. Until relatively recently, few methods have been able to fulfill these requirements, while simultaneously ensuring high-precision measurements. However, the rapid progress of technology has enabled certain physiological measurements to be carried out during experiments in the field. In this section, the physiological methods that can be applied in the laboratory and field experiments are briefly described.

\section{Measurement of central nervous activity}

As an index of central nervous activity, the authors have utilized cerebral hemodynamics estimated by near-infrared spectroscopy (NIRS) [3, 4]. NIRS is able to measure concentration changes in oxygenated and deoxygenated hemoglobin associated with brain activity with a 1-s time resolution by utilizing the difference in the infrared absorption properties between the two hemoglobin states. The sensors can be attached to the subject by means of double-sided tape without any difficulty and, therefore, less stress is caused by the measurement itself compared to other methods, such as electroencephalography. NIRS equipment is portable and sufficiently robust to be suitable for conducting measurements in the field. Nevertheless, adequate light shielding should be provided since the measurements are based on the principle of near-infrared light transmission.

The most recent feature of this method that makes it interesting is the possibility of measuring absolute hemoglobin concentration by using the time-resolved spectroscopy (TRS) technique [5, 6]. In earlier studies, NIRS could only be applied to measure relative changes in hemoglobin concentration from a certain baseline. However, with the development of techniques that measure the actual optical path length and solve a light diffusion equation using picosecond pulses, it is now possible to obtain an absolute value for hemoglobin concentration based on the assumption of the existence of homogenous optical properties beneath each optode. We have previously reported on the changes in absolute hemoglobin concentrations induced by walking or viewing scenery in forest and in urban environments [7]. To date, this is the only example of applying TRS in the field.

Measurement of autonomic nervous activity

Heart rate variability (HRV) [8] as well as blood pressure and pulse rate are frequently employed to estimate changes 
in the autonomic nervous activity. In experiments carried out by the authors, an ambulatory electrocardiogram monitor (AC301A; GMS Corp.) was attached to the subjects to store the data of the R-R interval for assessing HRV before, during, and after the subjects walked around or viewed the scenery in a forest area. The $\mathrm{R}-\mathrm{R}$ interval data were subsequently analyzed using the maximum entropy method [9] (Memcalc; GMS Corp.). The power of the low-frequency (LF; 0.04-0.15 Hz) and high-frequency (HF; $0.15-0.4 \mathrm{~Hz}$ ) components of the obtained heart rate power spectrum for each minute are generally calculated. HF power is considered to reflect parasympathetic nervous activity, and either $\mathrm{LF} / \mathrm{HF}$ or $\mathrm{LF} /(\mathrm{LF}+\mathrm{HF})$ is considered to be an index of sympathetic nervous activity [8]. Our results indicated that subjects in a forest environment had more enhanced parasympathetic and lower sympathetic nervous activity than those in an urban environment [10]. HRV analysis is thus a useful method for detecting the sympathetic and parasympathetic nervous activity separately on a minute-by-minute basis.

The newest technique for assessing autonomic nervous activity involves the measurement of salivary amylase activity. The secretion of salivary amylase is controlled by the sympathetic-adrenal-medullary system, and it has recently been determined that the secretion of salivary amylase under sympathetic nerve regulation may reflect mental stress, with increased secretion indicating higher stress [11]. Equipment that evaluates amylase activity onsite in 1 or 2 min has recently been developed [12] and is currently being tested in various studies, including our own. Since sampling of saliva causes considerably less stress in subjects than blood or urine sampling, there are high expectations for this method as a novel means of evaluating mental stress expressed via sympathetic nervous activity.

\section{Biomarkers reflecting stress response}

Salivary cortisol and immunoglobulin A (IgA) concentrations are established stress markers that are utilized in various scientific fields; however, few investigations have applied these indices to field studies involving a large number of subjects over a specific period of time. In our field studies, we have clarified that cortisol concentration is significantly lower in subjects exposed to a forest environment than in those exposed to an urban environment [10]. However, the results for $\operatorname{IgA}$ concentration were not consistent. IgA concentration is known to decrease under severe chronic stress [13], whereas it has been reported to increase in response to acute stress [14]. Interestingly, however, it has also been demonstrated that the levels of $\operatorname{IgA}$ in individuals engaged in stressful jobs are significantly higher than those in individuals who are not engaged in comparable activity [15]. It is thus believed that the use of $\operatorname{IgA}$ concentration as a stress marker should be re-evaluated by investigating the relationship between its change and the types and continuity of emotional stress.

There are large individual differences in the baseline values of salivary cortisol and salivary $\operatorname{IgA}$ concentrations. We recently found that there was a significant negative correlation between the baseline value and the amount of change in both salivary cortisol and IgA levels when subjects were walking and viewing scenery in both forest and city environments [16]. This finding will contribute to the interpretation of the individual differences in cortisol and IgA responses.

\section{Laboratory studies}

In this section, studies aimed at elucidating the effects of certain elements of the forest environment within the laboratory setting will be surveyed by reviewing the reports of previous studies. Prior to the "Therapeutic Effects of Forests" project, there had been little field research on "Shinrin-yoku." It is clear, nonetheless, that people have always recognized forests as familiar places and have somehow felt that the forest atmosphere benefitted human health. The number of studies targeting "Shinrin-yoku" gradually increased in the late 1990s following the launch of the "Shinrin-yoku plan" in 1982. Further, improvement in the technology of physiological measurements provided the impetus for an increase in the number of studies.

Forest environments affect humans via the five senses, providing stimulation of various senses, such as vision (scenery), olfaction (smell of wood), audition (sound of running streams or the rustle of leaves), tactile sensation (feel of the surfaces of trees and leaves). Sensory information inputs via the five senses are processed in the corresponding sensory areas of the brain and are further transmitted through interaction among the various sensory inputs. These signals subsequently reach the areas of the brain that control emotions and physiological functions, where they effect physiological changes. The objectives of the laboratory experiments that were designed to elucidate the physiological effects of each sensory input were: (1) to obtain backup data for the field studies or to undertake a detailed analysis of the results of these studies and (2) to assess the effects of elements of nature when subjects are introduced to an artificial environment (e.g., scenery shown in the form of a poster or smell introduced in the form of aroma therapy). Examples of laboratory-based studies that have investigated the therapeutic effects of wood and forest are summarized below. 


\section{Visual stimulation}

Suda et al. [17] investigated the physiological effects by viewing scenery of "Sakura" and "Shinrin-yoku" on 70inch high-resolution displays. Sakura consisted of a photograph of a cherry tree in full bloom, and Shinrin-yoku was a photograph of people taking a walk in the forest of Vincennes, Paris. In the subjective evaluation, the photograph of Shinrin-yoku was considered to be significantly more "comfortable" and "soothing" than the gray screen used as the control; in contrast, Sakura was evaluated as relatively "awakening." Subjects viewing Shinrin-yoku had a significantly decreased blood pressure and prefrontal activity, whereas those viewing Sakura had a significantly increased pulse rate and blood pressure. Further, viewing Sakura significantly increased activity in the prefrontal area. Although in certain cases there was a considerable correlation between the physiological responses and subjective evaluations, in other cases no such correlation was observed. In this particular study, however, there was a considerable correlation between the two. This study revealed that people experience elation on viewing cherry blossoms. It would be interesting to learn whether or not this physiological response is unique to Japanese.

Lee and Watanuki [18] investigated the differences between the cardiovascular responses of Types A and B subjects to visual stimulation of displeasure-evoking images and nature-video clips. Significant differences were observed in the heart rate and cardiac output between Types A and B persons when they viewed displeasureevoking images, i.e., Type A individuals showed a smaller decrease in heart rate and a significant increase in the cardiac output. However, in the "post-stress session" where the subjects watched the nature-video clips, no significant main effects of the Type A/B tendency or interactions between Type A/B tendency and type of visual stimulus were observed for any physiological recoveries. The authors assumed that nature-video clips may be effective in normalizing the stress-induced cardiovascular responses in Type A individuals as there were no differences between Types A and B subjects with respect to the physiological recovery responses.

Tsunetsugu et al. $[19,20]$ investigated the visual effects of wooden room interiors by evaluating physiological responses in mock-up living rooms. The objective of the study was to determine whether the wood ratio (i.e., the ratio of the area covered with wooden material to the whole area of the ceiling, walls, and floor) affected physiological responses. In this study, the authors attempt to focus attention solely on the visual effects; thus, they used veneer on the floor and walls of the rooms, and they ventilated the rooms appropriately. Subjects in a room with a $30 \%$ wood ratio, which is the standard type of living room commercially available in Japan [21] had a significantly decreased pulse rate and diastolic blood pressure, indicating the extent of the relaxing effect of this type of interior. A $45 \%$ wood ratio room tended to be evaluated as the most comfortable; further, when this wood ratio was utilized, the highest scores in the "vigorous" feeling in the mood test were generated. Pulse rate significantly increased in the $45 \%$ wood ratio room, which was considered to be in agreement with the results of the mood evaluation. A $90 \%$ wood ratio room initially caused a significant and large decrease in both systolic and diastolic blood pressure; however, this wood ratio subsequently led to a rapid decrease in prefrontal activity and an increase in pulse rate. In the subjective evaluation, all of the wooden interiors were rated as "comfortable"; however, physiological measurements revealed that an excessive amount of wood caused an awakened response. Consequently, the researchers hypothesized that there is an appropriate wood quantity (wood to room surface area ratio) in the presence of which people experienced physiological relaxation.

\section{Olfactory stimulation}

Phytoncides [derived from "phyto" (referring to plant) and "cide" (meaning "to kill")] are defined as volatile or nonvolatile substances produced by all types of plants that have an influence on other organisms [22]. The word phytoncide has become so popular that there is a persistent misunderstanding that the effects of "Shinrin-yoku" are solely attributable to phytoncide activity. However, phytoncide is a general name for a range of substances. These chemicals tend to differ from forest to forest. The atmospheric concentrations of phytoncides in forests are very low and vary depending on many factors, such as season, climate, and forest composition. This leads to the reasonable assumption that the effect of "Shinrin-yoku" is complex and comprises all of the elements associated with the senses, including phytoncides.

Phytoncides are olfaction-related elements of the forest environment. Smell has commonly been considered to be associated with instinct, emotion, and preference, and to have a greater influence on physiological change than stimuli for other senses [23].

Trees have scents that are species-specific. Japanese cedar (Cryptomeria japonica) is a representative tree species in Japan, and its smell is one of the most familiar to the Japanese population since cedar wood is frequently employed in the construction of houses. Miyazaki et al. [24] revealed that the smell of Japanese cedar chips significantly decreased systolic blood pressure, particularly at $40-60 \mathrm{~s}$ following the commencement of inhalation. The prefrontal area also exhibited a rapid decrease in activity with the inhalation of the smell of cedar chips, which 
became significant at 70-90 s following the first inhalation. The subjects evaluated the smell as "preferable." The smell of Japanese cedar wood improved subjective comfort and caused a relaxed physiological state.

There are large individual differences in odor preferences. In the experiment just described, although Japanese cedar was evaluated as "preferable" on average, there were some subjects who disliked the smell. However, contrary to expectation, there was no rise in the blood pressure of those subjects with an aversion to the smell. The authors assumed that human physiology has adapted to the natural environment and that the smell of natural matter does not lead to stress despite the fact that it is perceived as being unpleasant.

Hiba (Thujopsis dolabrata) is also a commonly used species in Japan that possesses a characteristic smell. Itai et al. [25] examined the effects of aromatherapy on the mood by exposing subjects to hiba oil and demonstrated that the smell of hiba oil significantly mitigated depression and anxiety in chronic hemodialysis patients. Hiruma et al. [26] investigated the effects of the odor of hiba on contingent negative variation $(\mathrm{CNV})$ and mismatch negativity (MNN). The amplitude of the CNV components was significantly larger under the odor condition than under the no-odor condition, while the amplitude of the MNN showed no difference whether or not the odor existed. The authors interpreted the results to be attributable to the nervous system being roused by the odor of hiba without affecting the autonomic information process.

Miyazaki et al. [27] reported the effects of the smell of Taiwan cypress (Chamaecyparis taiwanensis) on subjects. The inhalation of Taiwan cypress essential oil decreased the maximal blood pressure. In a work efficiency test in which the subjects deleted a specific character from a random character string, the odor of Taiwan cypress tended to improve task performance. The inhalation of Taiwan cypress essential oil appeared to relax the subjects, possibly enabling them to concentrate on the task.

One of the major components of wood scent, $\alpha$-pinene, is generally detected in the air of coniferous forests. Tsunetsugu et al. [28] investigated the effects of the concentration of $\alpha$-pinene on human physiological responses. Dilutions were made to obtain 10,100 , and $500 \mu \mathrm{L}$ of $\alpha$ pinene in $30 \mathrm{~L}$ of air. The odor was emitted at a rate of $3 \mathrm{~L} /$ min from a position approximately $15 \mathrm{~cm}$ beneath the nose of the subjects. The $10 \mu \mathrm{L} / 30 \mathrm{~L}$ and $100 \mu \mathrm{L} / 30 \mathrm{~L}$ concentrations, which were rated as "slight odor" and experienced to be "slightly comfortable" in the subjective evaluation, caused decreased systolic blood pressure. However, the $500 \mu \mathrm{L} / 30 \mathrm{~L}$ concentration, which was rated as a "strong odor" and "slightly uncomfortable," did not cause a decrease in systolic blood pressure although it did increase the pulse rate. The $500 \mu \mathrm{L} / 30 \mathrm{~L}$ concentration that caused the slightly uncomfortable experience was considered to induce dominant sympathetic nervous activity. It was also observed that the degree of increase in prefrontal activity was enhanced concomitant with the increase in the concentration of $\alpha$-pinene. Collectively, these results indicate that a weak smell of $\alpha$-pinene induces a relaxed physiological state, whereas a relatively strong smell of $\alpha$ pinene induces a stress state. Although $\alpha$-pinene is a natural product, human beings have likely never been exposed to relatively high concentrations of $\alpha$-pinene in the natural environment during evolution. Thus, it caused a stress state that was experienced as "uncomfortable."

Limonene is another common phytoncide of wood. It can also be found in citrus peel and has a lemony, grapefruitlike smell. Tsunetsugu et al. [28] demonstrated that limonene at a concentration of $10 \mu \mathrm{L} / 30 \mathrm{~L}$ emitted at a rate of $3 \mathrm{~L} / \mathrm{min}$ from a position approximately $15 \mathrm{~cm}$ beneath the nose of subjects was evaluated as being "slightly comfortable" and "slightly soothing." Blood pressure started to decrease after $20 \mathrm{~s}$ from the commencement of inhalation; this decrease reached a significant level at 33-44 s. These researchers concluded that the inhalation of limonene was experienced as comfortable and soothing and that it suppressed sympathetic nervous activity.

Dayawansa et al. [29] tested the effects of cedrol, which is a compound that occurs in cedar extract, on cardiovascular and respiratory functions and observed that cederol inhalation significantly decreased the heart rate, systolic blood pressure, diastolic pressure, and respiratory frequency. The authors assumed that cedrol inhalation reduced respiratory frequency, which in turn, decreased the blood pressure via an enhancement of the baroreceptor sensitivity that has been reported to be inversely related to sympathetic activity.

Despite the large number of studies, it remains unclear to date whether odor affects human physiology through the olfactory pathway or via the blood-borne route in the form of chemical compounds. Buchbauer et al. [30] reported that odorous compounds were observed in the serum of mice, though in low concentrations, after an inhalation of sedative odors. Dayawansa et al. [29] referred to both possibilities in their above-mentioned report that cedrol could act via the central olfactory and limbic systems, and/or via the blood-borne route or peripheral afferent fibers of the vagal nerve innervating the respiratory system. The most recent human study demonstrated that cedrol directly inhaled through the lower airway, but not introduced to the upper airway, causes a suppression of sympathetic outflow and an increase in parasympathetic outflow [31]. The results of various studies on other scents, such as lavender, lemon, valerian, and others, showed considerable agreement with respect to the fact that the effectiveness of odors in prolonging pentobarbital sleep time [32,33], lowering 
blood pressure [34], and suppressing renal sympathetic nerve activity [34] disappeared in anosmic mice or rats, thus indicating the mediation of the olfactory system in the whole process. The authors consider that odors affect human physiology mainly through the olfactory processing pathway; however, in the case of laboratory experiments, the possibility that odorous compounds act directly via the blood-borne pathway could not be eliminated since the concentration of inhaled compounds is relatively high. In the case of "Shinrin-yoku" performed in the field, where the odorous compounds (phytoncides) exist in very low atmospheric concentrations, it is likely that phytoncides exert their effects via the olfactory processing pathway, and not via the blood-borne route.

\section{Tactile sensation}

Among the elements of the forest environments, interior wood is considered to have the strongest association with tactile sensation. Sakuragawa et al. [35] attempted to clarify the effects of contact with wood used as an interior material. They compared the physiological responses shown by the subjects to a metal plate and an oak plate. The effect of the temperature of the materials was controlled by warming the metal plate and cooling the oak plate. The blood pressure of subjects was observed to increase when they touched the metal at room temperature; however, this increase was suppressed when the plate was warmed. The expectation was that the cold wood panel would cause an increase in blood pressure; however, it did not. In the subjective evaluation, the cold oak was felt to be uncomfortable but natural; this probably explains the suppression of a blood pressure increase.

Miyazaki et al. [36] reported on the effects of paint. They compared changes in systolic blood pressure caused by touching Japanese cedar panels that had not been painted, that had been painted with a thin layer (oil finish), and that had been painted with a thick layer (polyurethane paint). A metal plate was also prepared as a reference. In the case of no paint and thin paint, systolic blood pressure rose transiently and then rapidly fell back to baseline levels, whereas it remained high when the subjects touched the thick-painted panel and metal. These results indicate that cedar wood can be as much a stressor as metal when coated with a thick layer of paint. Wood is usually coated with paint for maintenance reasons; however, this tends to negate the comparative advantage of the material in terms of human-friendliness.

\section{Auditory stimulation}

Mishima et al. [37] compared the changes in brain activity and systolic blood pressure caused while listening to the sound of a turbine (dental implement), representing an artificial sound, or to a stream, representing a natural sound. No sound was introduced in the control session, i.e., the subjects heard no sound. Systolic blood pressure was significantly increased with the sound of the turbine; however, it was not changed by the sound of a stream. Prefrontal activity estimated using the NIRS method was considerably reduced when the subject was listening to the turbine, while it showed a slight but significant decrease when he/she was listening to the stream. Brain activity is frequently enhanced when stress is perceived; however, in this case, the sound of a turbine was so unpleasant that the flight reaction may have been induced. In the "Null" session, systolic blood pressure and cerebral activity did not show significant changes. The study was conceived with a view to masking the alarming sound of a turbine with the gentle sound of a stream; however, further studies on individual differences in physiological responses in terms of age, dental experiences and other factors would be required in order to be able to implement this idea into practice.

\section{Field studies on "Shinrin-yoku"}

Prior to the "Therapeutic Effects of Forests" project, methods for performing physiological measurements in the field had not been established, which is one of the reasons for the predominance of laboratory-based studies. However, as already mentioned, the rapid progress of technology has allowed researchers to apply certain physiological measurements to field studies. In this section, we first give an overview of the early field studies reported prior to the launching of the "Therapeutic Effects of Forests" project.

A further problem associated with field studies is that of reproducibility. Experimental conditions such as weather, temperature, among others are not controllable under field conditions. Consequently, large sample sizes are required to improve the signal-to-noise ratio. Given the amount of research funds and the number of staff required, the objective was to conduct a study on "Shinrin-yoku" on a national scale. Various elements, such as advances in the development of measurement techniques, increasing concern about stress and healing, and a new policy framework from the Forestry Agency to harness the multiple functions of forests, were well integrated to provide a firm foundation for the launch of the "Therapeutic effects of forests" project on a national scale.

The authors started to accumulate data from field experiments when a large project called the "Physiological Effects of Forest Environmental Components on Humans" was launched in 2004, supported by the Ministry of Agriculture, Forestry and Fisheries of Japan. The field experiments were 
continued in the "Therapeutic Effects of Forests" project that was initiated in 2005. A selection of the results that we obtained during the course of conducting the "Therapeutic Effects of Forests" project as well as other emerging studies will be introduced later in this section. Physical and chemical measurements conducted in addition to our physiological investigation will also be described.

\section{Past field studies on "Shinrin-yoku"}

Although limited, some field studies have been performed on "Shinrin-yoku" in the past.

Miyazaki et al. [38] conducted a study on Yakushima Island involving five subjects. This probably represents the first investigation of the physiological effects of "Shinrinyoku". In this study, the subjects entered the forest of Yakusugi, famed for its ancient cedar trees, and walked for $40 \mathrm{~min}$ in both the morning and the afternoon. They also walked for $40 \mathrm{~min}$ in a laboratory where temperature and humidity were set at the same levels as within the forest. The forest was perceived as "comfortable," "natural," and "relaxing." In the profile of mood states (POMS) test, the scores in the negative subscales, such as tension, depression, anger, fatigue, and confusion, were lowered; further, the score for vigor was increased. Salivary cortisol concentration, which is known to increase in response to stress, was lower in the forest than in the laboratory. Thus, the stress-reducing effect of "Shinrin-yoku" was revealed for the first time.

Ohtsuka et al. [39] examined the effect of "Shinrinyoku" on the blood glucose levels of 87 noninsulindependent diabetes mellitus patients (29 males and 58 females; average age 61 years). The patients were exposed to "Shinrin-yoku" (a 3- or 6-km walk depending on their physical ability and/or the existence of diabetic complications) nine times in 6 years. The number of occasions on which each subject participated in these sessions varied from one to nine, amounting to a total of 237 participantevents. Blood glucose levels measured after "Shinrinyoku" were significantly lower than those measured in the morning prior to "Shinrin-yoku" in all nine sessions; on average, it significantly decreased from 179 to $108 \mathrm{mg} / \mathrm{dL}$. The effect was found to be independent of the distance walked. The authors concluded that "Shinrin-yoku" was useful in the treatment of diabetes mellitus.

Ohira et al. [40] assessed the physiological effects of "Shinrin-yoku" on 20 student subjects. After exposure to a forest for $8 \mathrm{~h}$, natural killer (NK) cell activity and immunoglobulin A, G, and M levels were significantly increased; however, no changes were observed in other physiological parameters of the endocrine system, electroencephalography (EEG) and electrocardiography (ECG), or in psychological parameters. The authors speculated that the ambiguous results were due to the low temperatures in the forest attributable to bad weather.

Psychological effects of "Shinrin-yoku"

Morita et al. [41] investigated the psychological effects of forest environments with 498 respondents who visited a forest during 4 days of the survey. The survey revealed that the mood of the respondents (hostility, depression, liveliness, and three other positive and negative mood subscales) were significantly improved on the day of the forest visit compared to the control day, when the respondents did not visit a forested area. The authors also analyzed factors possibly related to the magnitude of "Shinrin-yoku" and found that the duration of the stay or other conditions associated with the forest visit were not linked to the degree of the effect; in contrast, based on self-rated psychological stress levels were linked to the degree of the effect, with those individuals who were chronically stressed experiencing greater beneficial effects.

\section{"Shinrin-yoku" in Seiwa Prefectural Forest Park, Chiba Prefecture [7]}

This study was conducted in a forest located within a reasonable distance of a populated area, namely the Seiwa Prefectural Forest Park, and also in the area around Chiba Station, which was used as a control. The predominant tree species in this forest is oak.

Subjects were asked to walk for $20 \mathrm{~min}$ in each area, and the absolute hemoglobin concentration, determined using the TRS technique, was found to be significantly lower in subjects walking in the forest area than in those walking in the urban area. It also tended to be lower in subjects in the forest area prior to viewing scenery, which may be attributed to the fact that the subjects had remained in the respective area since approximately 10:00 a.m. although measurements were performed between 2:10 p.m. and 3:00 p.m. These results indicate that the activity in the prefrontal area was reduced in subjects exposed to the forest area (Fig. 1). The salivary cortisol concentration, which is an indicator of stress levels, was significantly lower in subjects in the forest area than in subjects in the city area, both prior to and following viewing scenery in each area. Thus, the results of this study demonstrated that prefrontal activity was reduced and the concentration of the stress hormone was lowered in subjects exposed to a forest environment.

"Shinrin-yoku" in an old-growth broadleaf forest in Yamagata Prefecture [42]

Oguni Town in Yamagata Prefecture is situated on the border between Yamagata and Niigata, with forests 


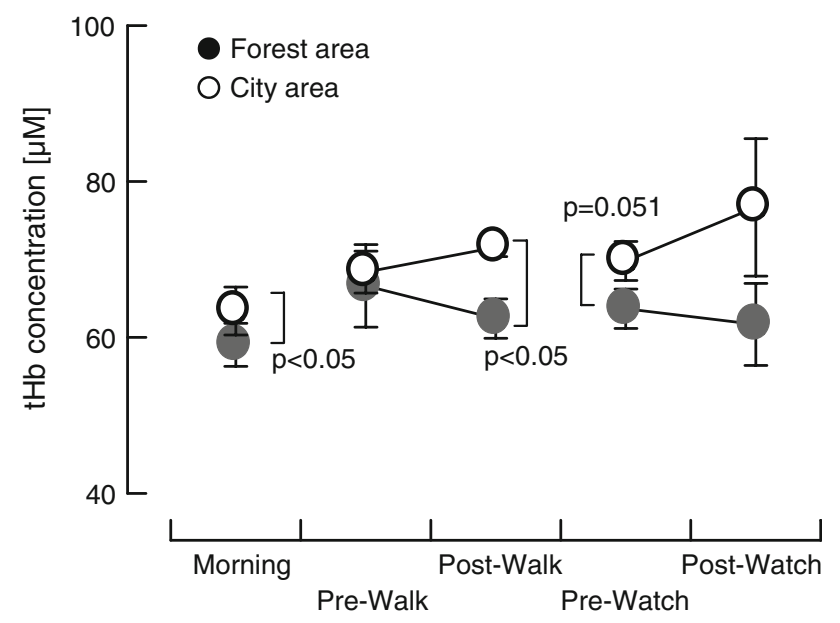

Fig. 1 Change in the average value of the absolute concentration of total hemoglobin $(t H b)$ in the left prefrontal area in subjects walking for $20 \mathrm{~min}$ in a forest and city area [7]. $n=5-12$, mean \pm SD, $p$ value by paired or unpaired $t$ test (one-side test)

covering $95 \%$ of the local area. This study was conducted in a deciduous broadleaf forest that mainly consisted of old-growth beech, with an area around Niigata Station used for comparison.

Systolic blood pressure was significantly lowered in subjects in the forest area prior to walking, and prior to and following viewing scenery compared with subjects in the urban area. Diastolic blood pressure was also lowered in subjects in the forest area prior to walking and following viewing scenery. The pulse rate was significantly lowered prior to walking and tended to be lowered following walking. There was a distinct difference in the cortisol concentrations of subjects between the two areas in that it was lower in the forest area than in the city area at all measurement times (Fig. 2). There was also a significant difference in cortisol levels between the two sites prior to and following walking, and following viewing of the scenery. The $p$ value was less than 0.06 prior to viewing. The results of the HRV analysis revealed that parasympathetic nervous activity was significantly higher and sympathetic nervous activity was significantly lower in subjects exposed to the forest environment. Thus, this study clearly demonstrated the relaxing and stress-relieving effects of "Shinrin-yoku."

The effects of "Shinrin-yoku" on immunological function

$\mathrm{Li}$ et al. are actively researching on the effects of forest environments on immunological function. They first elucidated, by conducting an in vitro experiment, that essential oil(s) or odorous components of wood, such as cypress (hinoki) stem oil, $\alpha$-pinene, and 1,8-cineole, significantly

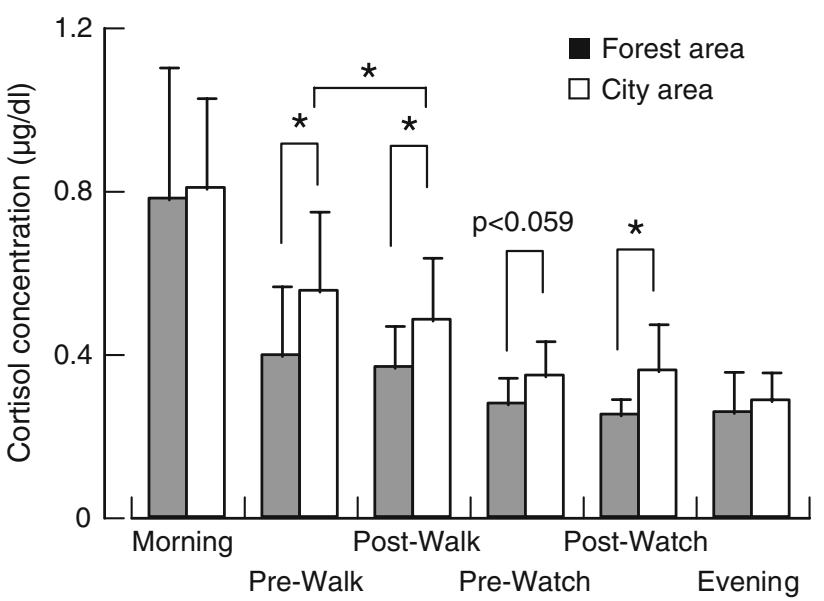

Fig. 2 Changes in salivary cortisol concentration at six measurement times in subjects a forest area and in a city area [42]. $n=9$ at "before walking" and "after walking", $n=11$ at the other times. $* p<0.05$ by the paired $t$ test

increased the NK activity, at least partially, via an increase in the intracellular levels of three cytolytic molecules, namely, perforin, granzyme A, and granulysin [43]. They subsequently conducted a field study with healthy male office-workers [44] and found that the NK activity of these office-workers significantly increased after they had experienced a 3-day/ 2-night stay in the forests. This enhancement in NK activity was at least partially mediated by an increase in the expression of the three cytolytic molecules mentioned above. These researchers also found that the effect of the forest environments on the NK activity lasted for more than 7 days following the trip, whereas a corresponding trip to an urban area did not cause any changes in NK activity [45]. Based on their most recent study, they report that similar results of increased and lasting NK activity after "Shinrin-yoku" were confirmed in female subjects [46].

Physical and chemical measurements

In the "Therapeutic Effects of Forests" project, measurements are also being carried out on the thermal and light environments, and volatile components (phytoncides) in the air are being evaluated. Takayama et al. [47], for example, calculated the predicted mean vote (PMV) value in forest and urban areas in the Chiba Prefecture study and reported that throughout the day, the forest environment provided more comfortable thermal conditions than the urban environment. The subjects evaluated the forested area to be as bright as the urban area, even though the illuminance in the forest was less than $5 \%$ of that in the city. The authors concluded that perceived brightness is not necessarily correlated with actual illuminance.

Ohira et al. [48] reported that among the volatile matters detected in coniferous forests, $\alpha$-pinene had the highest 
concentration. The detectable amounts of $\alpha$-pinene were high in cypress forests. Matsui et al. [49] described that large amounts of isoprene were detected in the air of broadleaf forests. For example, there were extremely large amounts of isoprene in the beech forest in the town of Oguni. The second most abundant substance was $\alpha$-pinene, although levels of this volatile were found to be less than $10 \%$ of the those of isoprene. These researchers as well as others have pointed out that there is a diurnal variation in the concentrations of these volatile matters and that weather may influence volatilization. It is expected that considerable advances in our understanding of phytoncides will be gained by adopting a large-scale approach as planned in "Therapeutic Effects of Forests" project.

\section{Future perspectives}

In order to firmly anchor "Shinrin-yoku" in our society and to fully exploit the therapeutic effects of forests by enjoying the benefits of "Shinrin-yoku" on a daily basis, the accumulation of data based on scientific evidence should be continued. A desirable step would be to increase the variety of types of forest settings appropriate for "Shinrin-yoku". This should be linked to a requirement for "Shinrin-yoku" programs that are customized for individuals by experts and for simple physiological indices that enable on-the-spot evaluations of the effects of "Shinrinyoku." Future studies will focus on individual differences and the development of novel systems used to evaluate the effects of "Shinrin-yoku."

Research on the effects of individual differences, such as age, physical strength, personal preference, physiological character, and personality, are required to enable experts to devise individually tailored "Shinrin-yoku" programs. While individual differences are a matter of continuing concern in human studies, data have typically been treated as "an average value and outlier values" owing to methodological difficulties. Research that scientifically treats individual differences based on the view that "within any group of people certain physiological subgroups will exist," will be warranted in the future.

In addition to blood pressure and pulse rate, biomarkers in saliva are considered to be potential candidates as simple indices by which to assess the effects of "Shinrin-yoku." As a consequence of recent improvements in measurement accuracy, other indices, such as cortisol and immunoglobulin A, can be currently used at saliva biomarkers. Further, indices such as salivary amylase activity [12] and chromogranin A [50,51] are considered to be potential new stress markers. We are currently accumulating data with a simple instrument that estimates the amylase activity in saliva for 1 or 2 min using a recently developed technique.
The reliability of this index could be further enhanced by continuing fundamental analysis of diurnal variation and/or individual difference in baseline concentrations.

Although the aim of our review was to focus on research that has been carried out in Japan or is currently being carried out, an increasing number of studies are now emerging in various countries [52-58]. Thus far, these have been mostly psychological investigations; however, some of them refer to the importance of physiological investigations. The effects of forest environments on human health are expected to be verified by international efforts.

Acknowledgments This review was partly supported by Grant-inAid for Scientific Research (S:16107007) from The Ministry of Education, Culture, Sports, Science and Technology (MEXT).

\section{References}

1. Ministry of Health, Labour and Welfare, Japan. Trend survey on health and welfare in Japan; 2000.

2. Frumkin H. Beyond toxicity: human health and the natural environment. Am J Prev Med. 2001;20(3):234-40.

3. Villringer A, Chance B. Non-invasive optical spectroscopy and imaging of human brain function. Trends Neurosci. 1997;20(10): 435-42.

4. Shaw RA, Mansfield JR, Kupriyanov VV, Mantsch HH. In vivo optical/near-infrared spectroscopy and imaging of metalloproteins. J Inorg Biochem. 2000;79:285-93.

5. Oda M, Yamashita Y, Nakano T, Suzuki A, Shimizu K, Hirano I, et al. Near-infrared time-resolved spectroscopy system for tissue oxygenation monitor. Proc SPIE. 2000;4160:204-10.

6. Ohmae E, Ouchi Y, Oda M, Suzuki T, Nobesawa S, Kanno T, et al. Cerebral hemodynamics evaluation by near-infrared timeresolved spectroscopy: Correlation with simultaneous positron emission tomography measurements. Neuroimage. 2006;29(3): 697-705.

7. Park BJ, Tsunetsugu Y, Kasetani T, Hirano H, Kagawa T, Sato $\mathrm{M}$, et al. Physiological effects of Shinrin-yoku (taking in the atmosphere of the forest)-using salivary cortisol and cerebral activity as indicators. J Physiol Anthropol. 2007;26(2):123-8.

8. Task Force of the European Society of Cardiology the North American Society of Pacing Electrophysiology. Heart rate variability. Standards of measurement, physiological interpretation, and clinical use. Circulation. 1996; 93:1043-65.

9. Ohtomo N, Terachi S, Tanaka Y, Tokiwano K, Kaneko N. New method of time series analysis and its application to Wolf's sunspot number data. Jpn J Appl Phys. 1994;33:2821-31.

10. Park BJ, Tsunetsugu Y, Morikawa T, Ishii H, Furuhashi S, Hirano $\mathrm{H}$, et al. Physiological effects of Shinrin-yoku (taking in the atmosphere of the forest) (5) Results of field tests at 24 sites throughout Japan. J Physiol Anthropol. 2007;26(6):608.

11. Chatterton RT Jr, Vogelsong KM, Lu YC, Ellman AB, Hudgens GA. Salivary alpha-amylase as a measure of endogenous adrenergic activity. Clin Physiol. 1996;16(4):433-48.

12. Yamaguchi M, Deguchi M, Wakasugi J, Ono S, Takai N, Higashi $\mathrm{T}$, et al. Hand-held monitor of sympathetic nervous system using salivary amylase activity and its validation by driver fatigue assessment. Biosens Bioelectron. 2006;21(7):1007-14.

13. Martin RA, Dobbin JP. Sense of humor, hassles, and immunoglobulin. A evidence for a stress-moderating effect of humor. Int J Psychiatry Med. 1988;18(2):93-105. 
14. Yamada F, Miyata Y, Takenaka K, Tanaka K. Secretory IgA as an index of stress reactivity (in Japanese). Bull Osaka Prefect Coll Nurs. 1995;1(1):47-50.

15. Henningsen GM, Hurrell JJ Jr, Baker F, Douglas C, MacKenzie BA, Robertson SK, et al. Measurement of salivary immunoglobulin $\mathrm{A}$ as an immunologic biomarker of job stress. Scand $\mathbf{J}$ Work Environ Health. 1992;18 Suppl. 2:133-6.

16. Tsunetsugu Y, Miyazaki Y. Correlation between baseline value and amount of change in salivary cortisol concentration and salivary immunoglobulin A concentration. J Physiol Anthropol. 2007;26(6):612.

17. Suda R, Yamaguchi M, Hatakeyama E, Kikuchi T, Miyazaki Y, Sato M. Effect of visual stimulation (I)-in the case of good correlation between sensory evaluation and physiological response. J Physiol Anthropol Appl Hum Sci. 2001;20(5):303.

18. Lee JM, Watanuki S. Cardiovascular responses of Type A and Type B behavior patterns to visual stimulation during rest, stress, and recovery. J Physiol Anthropol. 2007;26(1):1-8.

19. Tsunetsugu Y, Miyazaki Y, Sato H. Visual effects of interior design in actual-size living rooms on physiological responses. Build Environ. 2005;40(10):1341-6.

20. Tsunetsugu Y, Miyazaki Y, Sato H. Physiological effects in humans induced by the visual stimulation of room interiors with different wood quantities. J Wood Sci. 2007;53(1):11-6.

21. The Government Housing Loan Corporation, Japan. Survey on architectural details of the one-unit houses using government housing loan; 1992.

22. Tokin BP, Kamiyama K. A Mysterious phytoncide in plants (in Japanese). Tokyo, Kodansha; 1980.

23. Takagi S, Shibuya T. Science of smell (in Japanese). Tokyo: Asakura Publishing Co.; 1989.

24. Miyazaki Y, Morikawa T, Yamamoto N. Effect of wooden odoriferous substances on humans. J Physiol Anthropol Appl Hum Sci. 1999;18(5):189.

25. Itai T, Amayasu H, Kuribayashi M, Kawamura N, Okada M, Momose A, et al. Psychological effects of aromatherapy on chronic hemodialysis patients. Psychiatry Clin Neurosci. 2000;54(4):393-7.

26. Hiruma T, Yabe H, Sato Y, Sutoh T, Kaneko S. Differential effects of the hiba odor on CNV and MMN. Biol Psychol. 2002;61(3):321-31.

27. Miyazaki Y, Motohashi Y, Kobayashi S. Changes in mood by inhalation of essential oils in humans II. Effect of essential oils on blood pressure, heart rate, R-R intervals, performance, sensory evaluation and POMS (in Japanese). Mokuzai Gakkaishi. 1992;38(10):909-13.

28. Tsunetsugu Y, Morikawa T, Miyazaki Y. The relaxing effect of the smell of wood (in Japanese). Wood Ind. 2005;60(11):598-602.

29. Dayawansa S, Umeno K, Takakura H, Hori E, Tabuchi E, Nagashima $\mathrm{Y}$, et al. Autonomic responses during inhalation of natural fragrance of Cedrol in humans. Auton Neurosci. 2003;108(1-2):79-86.

30. Buchbauer G, Jirovetz L, Jäger W, Plank C, Dietrich H. Fragrance compounds and essential oils with sedative effects upon inhalation. J Pharm Sci. 1993;82(6):660-4.

31. Umeno K, Hori E, Tsubota M, Shojaku H, Miwa T, Nagashima $\mathrm{Y}$, et al. Effects of direct cedrol inhalation into the lower airway on autonomic nervous activity in totally laryngectomized subjects. Br J Clin Pharmacol. 2008;65(2):188-96.

32. Tsuchiya T, Tanida M, Uenoyama S, Nakayama Y, Ozawa T. Effects of olfactory stimulation on the sleep time induced by pentobarbital administration in mice. Brain Res Bull. 1991;26(3): 397-401.

33. Komori T, Matsumoto T, Motomura E, Shiroyama T. The sleepenhancing effect of valerian inhalation and sleep-shortening effect of lemon inhalation. Chem Senses. 2006;31(8):731-7.
34. Tanida M, Niijima A, Shen J, Nakamura T, Nagai K. Olfactory stimulation with scent of lavender oil affects autonomic neurotransmission and blood pressure in rats. Neurosci Lett. 2006;398(1-2):155-60.

35. Sakuragawa S, Kaneko T, Miyazaki Y. Effects of contact with wood on blood pressure and subjective evaluation. J Wood Sci. 2008;54(2):107-13.

36. Miyazaki, Morikawa T, Sueyoshi S. Effect of touching to wood on humans. J Physiol Anthropol Appl Hum Sci. 1999;18(5):189.

37. Mishima R, Kudo T, Tsunetsugu Y, Miyazaki Y, Yamamura C, Yamada Y. Effects of sounds generated by a dental turbine and a stream on regional cerebral blood flow and cardiovascular responses. Odontology. 2004;92(1):54-60.

38. Miyazaki Y, Motohashi Y. Forest environment and physical response. In: Agishi Y, Ohtsuka Y, editors. Recent progress in medical balneology and climatology. Hokkaido: Hokkaido University; 1995. p. 67-77.

39. Ohtsuka Y, Yabunaka N, Takayama S. Shinrin-yoku (forest-air bathing and walking): effectively decreases blood glucose levels in diabetic patients. Int J Biometeorol. 1998;41(3):125-7.

40. Ohira H, Takagi S, Masui K, Oishi M, Obata A. Effect of Shinrinyoku (forest-air bathing and walking): On mental and physical health (in Japanese). Bull Tokai Women's Coll. 1999;19:217-32.

41. Morita E, Fukuda S, Nagano J, Hamajima N, Yamamoto H, Iwai $\mathrm{Y}$, et al. Psychological effects of forest environments on healthy adults: Shinrin-yoku (forest-air bathing, walking) as a possible method of stress reduction. Public Health. 2007;121(1):54-63.

42. Tsunetsugu Y, Park BJ, Ishii H, Hirano H, Kagawa T, Miyazaki Y. Physiological Effects of Shinrin-yoku (Taking in the Atmosphere of the Forest): In an Old-Growth Broadleaf Forest in Yamagata Prefecture, Japan. J Physiol Anthropol. 2007;26(2): 135-42.

43. Li Q, Nakadai A, Matsushima H, Miyazaki Y, Krensky AM, Kawada T, et al. Phytoncides (wood essential oils) induce human natural killer cell activity. Immunopharmacol Immunotoxicol. 2006;28(2):319-33.

44. Li Q, Morimoto K, Nakadai A, Inagaki H, Katsumata M, Shimizu $\mathrm{T}$, et al. Forest bathing enhances human natural killer activity and expression of anti-cancer proteins. Int $\mathbf{J}$ Immunopathol Pharmacol. 2007;20(2 Suppl 2):3-8.

45. Li Q, Morimoto K, Kobayashi M, Inagaki H, Katsumata M, Hirata Y, et al. Visiting a forest, but not a city, increases human natural killer activity and expression of anti-cancer proteins. Int J Immunopathol Pharmacol. 2008;21(1):117-27.

46. Li Q, Morimoto K, Kobayashi M, Inagaki H, Katsumata M, Hirata $\mathrm{Y}$, et al. A forest bathing trip increases human natural killer activity and expression of anti-cancer proteins in female subjects. J Biol Regul Homeost Agents. 2008;22(1):45-55.

47. Takayama N, Kagawa T, Kasetani T, Park BJ, Tsunetsugu Y, Oishi Y, et al. The comfortableness of the light/thermal environment for bathing in the forest atmosphere (in Japanese). Land Res J. 2005;68(5):819-24.

48. Ohira T, Matsui N, Takayama N, Kagawa T, Koyama Y, Fujisawa M, Masaki S. Volatile substances released from forests II (in Japanese). Abstracts 2005 Annu Meet Chub Branch Jpn Wood Res Soc. Japanese Wood Research Society, 2005; 64-5.

49. Matsui N, Ohira T, Takayama N, Inoue M, Kagawa T, Koyama T. Volatile substances released from forests III (in Japanese). Abstracts 2005 Annu Meet Chub Branch Jpn Wood Res Soc. Japanese Wood Research Society, 2005; 66-7.

50. Toda M, Makino H, Kobayashi H, Morimoto K. Health effects of a long-term stay in a spa resort. Arch Environ Occup Health. 2006;61(3):131-7.

51. Kanamaru Y, Kikukawa A, Shimamura K. Salivary chromogranin-A as a marker of psychological stress during a cognitive test battery in humans. Stress. 2006;9(3):127-31. 
52. Hartig T, Evans GW, Jamner LD, Davis DS, Gärling T. Tracking restoration in natural and urban field settings. J Environ Psychol. 2003;23:109-23.

53. Herzog TR, Maguire CP, Nebel MB. Assessing the restorative components of environments. J Environ Psychol. 2003;23:15970.

54. Korpela KM, Hartig T, Kaiser FG, Fuhrer U. Restorative experience and self-regulation in favorite places. Environ Behav. 2001;33(4):572-89.

55. Lauman K, Gärlin T, Stormark KM. Selective attention and heart rate responses to natural and urban environments. J Environ Psychol. 2003;23:125-34.
56. Shin WS, Kwon HG, Hammitt WE, Kim BS. Urban forest park use and psychosocial outcomes: a case study in six cities across South Korea. Scand J For Res. 2005;20(5):441-7.

57. Shin WS. The influence of forest view through a window on job satisfaction and job stress. Scand J Forest Res. 2007;22(3):24853.

58. Van den Berg AE, Koole SL, Wulp NY. Environmental preference and restoration: (How) are they related? J Environ Psychol. 2003;23:135-46. 